\title{
Sexual Behavior in Peripherally Anosmic Male Hamsters ${ }^{1}$
}

\author{
J. BRADLEY POWERS AND SARAH S. WINANS
}

Neuroscience Laboratory and Department of Anatomy, University of Michigan, Ann Arbor, Michigan 48104

(Received 22 September 1972)

\begin{abstract}
POWERS J. B. AND S. S. WINANS. Sexual behavior in peripherally anosmic male hamsters. PHYSIOL. BEHAV 10(2) $361-368,1973$.-Sexually experienced and inexperienced male hamsters mated normally after they had been rendered temporarily anosmic by intranasal zinc sulfate treatment (Experiment 1), in contrast to the complete absence of sexual behavior following removal of the olfactory bulbs. The efficacy of our zine sulfate technique was demonstrated by use of an olfactory discrimination training procedure. Hamsters lost the ability to smell both amyl acetate (Experiment 2) and the female hamster post-estrus vaginal discharge (Experiment 3) following zinc sulfate induced anosmia but at the same time retained normal sexual behavior.
\end{abstract}

Sex behavior Hamster Anosmia Olfaction

THE variables which may affect male sexual behavior have been studied by a number of investigators $[8,18,41,67]$. It is commonly thought that central and peripheral effects of androgen must be coupled with appropriate sources of arousing stimulation in order for normal patterns of behavior to occur. The complexity and redundancy of mechanisms which govern male copulatory behavior is reflected in the fact that very few experimental treatments, besides castration and some central lesions, can interfere in any drastic fashion with its occurrence $[9,25]$. Recently it has been demonstrated that mating behavior in male hamsters and mice can be totally abolished by removal of the olfactory bulbs $[19,39,47,57]$. This would appear to contradict the above generalization and the assertion that no one sensory modality is critical for sexual behavior [7].

A variety of changes have been demonstrated following bulbectomy in both sexual $[10,30,32,45,65]$ and other social behaviors $[4,5,24,35,56]$. However, it is not clear whether these behavioral changes result from an inability to detect olfactory stimuli or from other consequences of olfactory tissue destruction. Besides producing anosmia, bulbectomy as it is typically performed removes input from the vomeronasal organ to the accessory olfactory bulb [44] and disrupts olfactory bulb interactions with the limbicmidbrain system which might be important in regulating a variety of behaviors.

The possible importance of the vomeronasal organaccessory olfactory bulb system became apparent when it was demonstrated that the neural projections of the accessory bulb, but not of the main olfactory bulb, terminated in the medial nucleus and the medial portion of the cortical nucleus of the amygdala [68]. This accessory bulb projection field contains cells whose fibers run in the stria terminalis and synapse in the preoptic area and medial hypothalamus $[21,31,36]$. Thus there is anatomical evidence to suggest that sensory input via the vomeronasal system could influence diencephalic areas known to be important in the regulation of male sexual behavior [17, $25,29,37,38,42]$.

Although rabbits were used in the original anatomical demonstration that the main and accessory olfactory bulbs have separate projections, preliminary evidence (unpublished observations) suggests that this dual projection system is also characteristic of the hamster, one of the two species in which bulbectomy (generally including both the main and accessory bulbs) is known to eliminate male sexual behavior. It therefore seemed appropriate to use the hamster in order to elucidate the contributions of: (1) the peripheral olfactory system; (2) the vomeronasal accessory olfactory bulb system; and, (3) olfactory bulb-limbic system interactions in producing the loss of copulatory behavior following olfactory bulb removal. This report concerns experimental approaches to the first of these questions.

In Experiment 1, the effects of a modified zinc sulfate procedure for inducing peripheral anosmia [2] were evaluated in both sexually experienced and inexperienced males, and in Experiments 2 and 3, the efficacy of this technique for producing anosmic animals was investigated by utilizing tests of olfactory discrimination. We found that removal of the sense of smell in male hamsters in no way affects their ability to display normal patterns of copulatory behavior. \footnotetext{
${ }^{1}$ We especially thank Elliot S. Valenstein for many helpful discussions throughout the course of these experiments. Research supported by
NIMH Grant No. MH20811 to E.S.V.
} 
EXPERIMENT

\section{Materials and Method}

Nineteen male hamsters weighing between 75-85 grams were obtained from Con Olson Co. (Madison, Wisconsin) and housed individually with Purina lab chow and water provided ad lib under a reversed illumination schedule (lights off between 9 a.m. and 9 p.m.). After approximately 2 weeks, animals were randomly assigned to one of two groups; one group received sexual experience but the second group did not. Hamsters in the experience group (EXP) ware allowed to copulate with estrous females three times per week on alternate days for two successive weeks. Behavioral estrus was induced in ovariectomized females by sequential subcutaneous injections of estradiol benzoate $(10 \mu \mathrm{g})$ and progesterone $(200 \mu \mathrm{g})$ dissolved in sesame oil and administered 42 , and $6 \mathrm{hr}$, respectively, before behavior testing. (Progynon Benzoate and Proluton were generously supplied by the Schering Corporation, Bloomfield, N.J.). These females were routinely checked with stud males to assure that lordosis could be easily elicited. Testing sessions occurred during the dark portion of the illumination cycle and lasted 10 min or until the male had achieved 2 ejaculations. All mounts, intromissions and ejaculations were scored on a Rustrak event recorder. Sexual behavior was evaluated in terms of the latency between introduction of the female and the first intromission (IL), the comparable latency to first ejaculation (EL) and the number of intromissions preceding ejaculation $(\mathrm{I} / \mathrm{E})$. Tests were conducted in clear Plexiglas boxes measuring $24 \times 30 \mathrm{~cm}$ in area and $21 \mathrm{~cm}$ high. Each male was placed in a test box for 5 min prior to introducing an estrous female. To control for handling, each male in the group receiving no sexual experience (INEXP) was placed in a mating box for $10 \mathrm{~min}$ in the absence of an estrous female on the same days the EXP males were given sexual experience. All males in the EXP group ejaculated during at least 3 of the 6 sessions.

Either 3 or 4 days after the final experience session, peripheral anosmia was induced in 6 of the $10 \mathrm{EXP}$ and in 5 of the 9 INEXP animals. The remaining hamsters in each group were administered a control procedure. Periphera] anosmia was induced by an intranasal zinc sulfate solution using a technique modified from the one described by Alberts and Galef [2]. The coagulation necrosis of olfactory mucosa produced by this treatment has been described by Smith [63], Schultz [60], and Mulvaney and Heist [46], and its effect on olfactory discrimination ability is reported in Experiments 2 and 3 .

Figure 1 depicts the hook and insert combination which was used to apply zinc sulfate. An outer hook served to guide a partially fexible inner assembly into the posterior region of the nasal cavities. Using this system, solutions could be passed from a hypodermic syringe, through the inner assembly tubing, and onto the olfactory mucosa with relative ease.

Hamsters were anesthetized with ether and placed on their backs with head lowered in an inclined position. The outer tube with insert retracted was slid over the hard palate until the bent end entered the nasopharyngeal meatus. The insert was then extended and attached to a 1 $\mathrm{ml}$ syringe so that $0.5 \mathrm{ml}$ of $5 \%$ zinc sulfate in $0.5 \%$ saline could be passed through the nasal cavities. The solution was aspirated at the external nares during the entire period of zinc sulfate delivery and for approximately $10 \mathrm{sec}$ after-

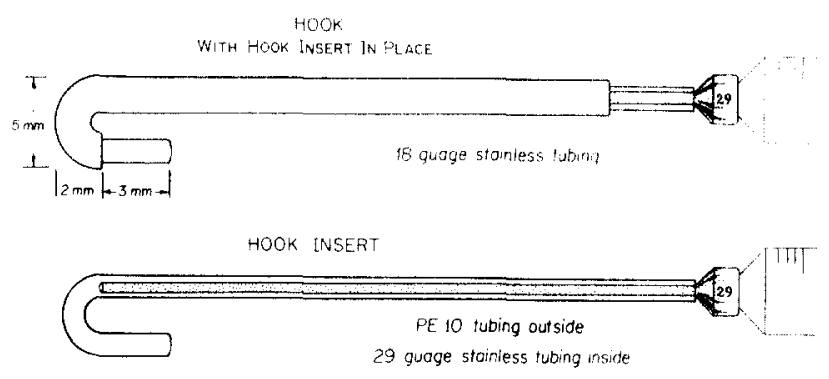

FIG. 1. Hook and insert assembly used for passing zinc sulfate solution over the olfactory mucosa of hamsters. See text for procedural details.

wards. For control purposes, $0.5 \%$ saline alone was administered using the same procedures.

Males in the EXP group were assigned to zinc sulfate or saline treatments so as to balance the total number of ejaculations achieved during the 6 experience sessions. Inexperienced males were assigned by equating body weights between the 2 groups. Two days following the intranasal application of zinc sulfate or saline, sexual behavior tests were given to all males using the same procedures as were employed in the experience sessions. The 2-day interval between zinc sulfate and behavior testing was chosen to allow any transient general debilitating efiects of zinc sulfate to dissipate.

\section{Results}

Zinc sulfate treatment had no effect on the copulatory performance of male hamsters under our testing conditions (Fig. 2). These males were not significantly different from saline controls on any of the 3 behavioral measures in either the sexually experienced or inexperienced groups.

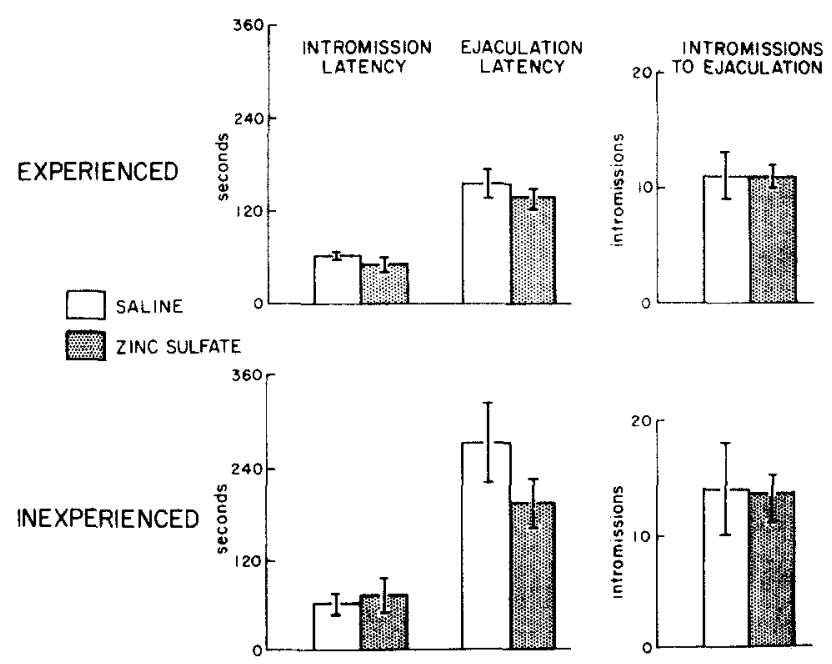

FIG. 2. Sexual behavior scores (mean \pm standiard error of the mean) of sexually experienced (EXP) and inexperienced (INEXP) male hamsters after receving intranasal saline (S) or zinc sulfate (ZS) treatment. N's were $\mathrm{EXP} / \mathrm{S}=4$ and $\mathrm{EXP} / \mathrm{ZS}=6: \mathrm{INEXP} / \mathrm{S}=4$ and INEXP/ZS $=5$ 
Although IL and I/E scores were nearly identical for the EXP and INEXP saline treated animals, the EL was considerably longer for inexperienced males and approached significance ( $p=0.057$; Mann-Whitney $\mathrm{U}$ test). The comparable difference between EXP and INEXP zinc sulfate treated animals was smaller.

\section{EXPERIM ENT 2}

The results of Experiment 1 are consistent with the hypothesis that impairment of olfactory function does not interfere with male sexual behavior in hamsters. However, independent assessment of olfactory deficits were not carried out. The purpose of Experiment 2 was to ascertain that peripheral anosmia was successfully induced by intranasal zinc sulfate administration and that male hamsters would mate normally during the experimentally established period of anosmia.

\section{Materials and Method}

Male hamsters weighing $100 \mathrm{~g}$ were obtained from Con Olson Co. and housed under conditions identical to those described for Experiment 1 except that the colony lights were off between noon and midnight. Fourteen animals were water deprived and trained in a $Y$ maze to learn the position of a water reward on the basis of odor cues. Generally, the experimental paradigm consisted of training animals to a criterion performance level and then testing whether this olfactory discrimination would be maintained first following an intranasal saline control procedure and later after zinc sulfate had been administered. Sexual behavior was tested both before and after zinc sulfate treatment.

A schematic drawing of the apparatus used, modified after one described by Bowers and Alexander [11], is shown in Fig. 3. The essential features of this enclosed maze consist of a blower to pass air through 2 flasks into the ends of the 2 goal arms, and an exhaust fan positioned behind the start box, to quickly remove the odorized air. The odorant source consisted of 15 drops of amyl acetate (mixed isomers) in a small cotton ball placed at the bottom of Flask B. Flask A contained a clean cotton ball only. A ir was passed from the blower through the flasks and into the maze via rubber tubing with quick disconnect connectors at $C$, which allowed the tube carrying odorized air to be switched easily from one goal arm to the other.

The water reward was always on the side containing the odorant; this side was randomly varied according to a Gellerman series. Training took place under approximately $23 \mathrm{hr}$ of water deprivation; one hour of ad lib drinking was allowed in the home cage following the daily training session. Each trial was run by placing a hamster in the start box and activating the blower for $10 \mathrm{sec}$ before the start box door was opened. The blower remained on until after the animal had made a choice. If the choice was correct, the blower stayed on until the water cup was reached; when incorrect choices were made, the blower was turned off after the goal arm entrance had been traversed. Between trials, animals were placed in a holding box while the apparatus was exhausted in preparation for the next run. All hamsters were given 15 trials per day for 5 days each week until a criterion of at least 13 correct responses per day over 2 successive training days was met.

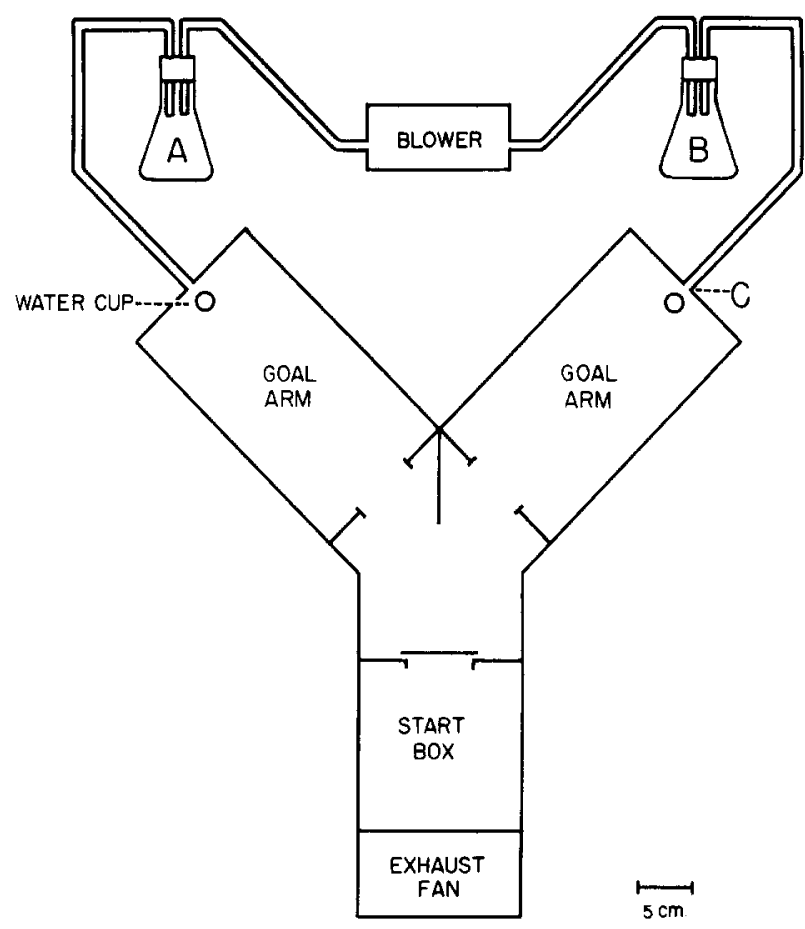

FIG. 3. Schematic overhead depiction of an enclosed, plexiglas $Y$ maze used to assess the olfactory discrimination ability of male hamsters. Odorants were placed in Flask B (Flask A remained free of odor) and could be delivered to either goal arm by means of

"quick disconnect" junctions (C). See text for procedural details.

At some point prior to the attainment of this criterion, all hamsters were given a single sex test (as described in Experiment 1) to assure that they were capable of displaying normal copulatory behavior. If an animal did not attain 2 ejaculations within a 5 min test it was not continued in the experiment.

On the day olfactory discrimination criterion was met, the saline control procedure was administered to determine whether etherization, the passage of solution over the olfactory mucosa, or a 48-hr period without training would affect discrimination performance. Water was available ad lib for $24 \mathrm{hr}$ following the control procedure but the $23 \mathrm{hr}$ deprivation schedule was reinstated thereafter. Two control olfactory discrimination tests were run 48 and $72 \mathrm{hr}$ after saline treatment. Following the 72 -hr test, zinc sulfate was applied as described in Experiment 1. The availability of water and resumption of olfactory testing was identical to that after saline except that testing was carried out for 8 consecutive days or until criterion had been remet. Not all of the 14 animals in this experiment received both the control and zinc sulfate procedures according to the schedule described above. Six animals were administered the experimental procedure only, with no prior saline control, and 3 animals received the control treatment only. In all these cases the procedure administered was given on the day criterion performance was attained and subsequent olfactory testing was carried out as described above.

All animals that received zinc sulfate were given a single sex behavior test $48 \mathrm{hr}$ following this treatment, i.e., immediately after the first post-zinc sulfate olfactory 
discrimination testing session. The procedures used in these tests were identical to those described for Experiment 1.

\section{Results}

Male hamsters learned to discriminate the position of amyl acetate odorized air in a mean of 137 trials ranging between 75 and 225. These results are shown in Fig. 4 which depicts mean performance scores of all hamsters studied, whether the animal was given saline, zinc sulfate, or both in succession, after initial learning. Correct choices were plotted backwards from the day on which criterion was met in order to compensate for the variability in the number of trials necessary to reach criterion. Olfactory discrimination performance was not distupted by the saline control procedures. The mean number of correct responses on the two days of criterion performance and the two days following intranasal saline was 13.7 and 13.2 , respectively. Zinc sulfate administration caused an obvious olfactory deficit; performance scores dropped to chance levels on the first test following this treatment for all except one animal ( $p<.005$, Wilcoxon test). However, this hamster did perform at chance over the succeeding 3 days. On none of the test days did the animals appear debilitated nor lose weight; they ran normally in the maze and vigorously consumed the water when correct choices were made.

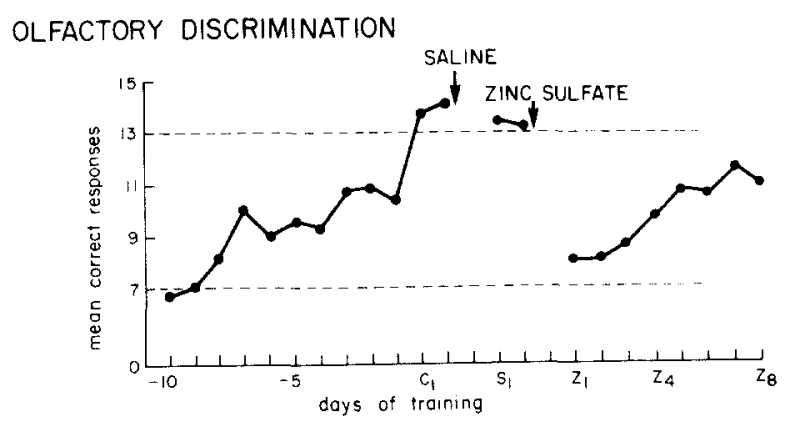

MATING BEHAVIOR

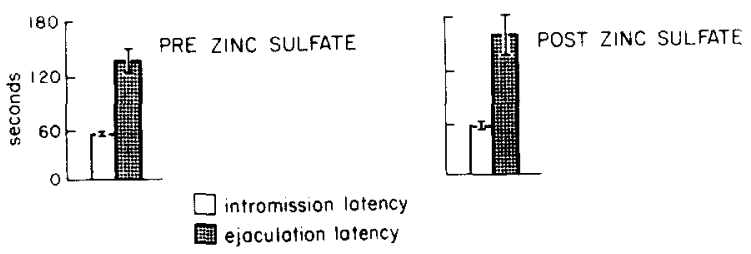

FIG 4. Olfactory discrimination performance ( 15 trials/day) during initial learning, after intranasal saline, and after intranasal zinc sulfate. (See text and Table 1 for N's). Mating behavior scores (means + standard error of the mean), from 5 min tests given before, and 2 days after zinc sulfate treatment $(\mathrm{N}=11)$.

After approximately the third post-zinc sulfate test day (5 days after zinc sulfate administration), some hamsters began to show signs of recovered olfactory function. Two animals reached criterion again within 7 days, one by 8 days, and 2 could have done so by 9 days if additional testing had been given. This recovery of olfactory function following zinc sulfate application has been reported in the rat [2] and corresponds with the time course of the regeneration of receptor cells in the offactory epithelum an rabbits [46]

Male sexual behavior was tested 48 hr after the zin sulfate had been administered. On this day when the first post-zinc sulfate olfactory discrimination test was given, olfactory function was seriously impaired but copulatory performance was not. Intromission and ejaculation latencies after peripheral anosmia had been induces were nol significantly different from sexual performance levels dur. ing control tests (Fig. 4). The mean number of intromissions to ejaculation, before and after zinc sulfate treatment was 8.7 and 13.9 , respectively. Although 1 animal contributed disproportionately to the higher post-zinc sulfate $/ / L$ mean, the majority of subjects did require more intromissions to reach ejaculation while anosmic $(1)<0.05$, Wilcoxon test).

\section{EXPERIM FN T 3}

Experiment 2 demonstrated that our procedure for passing zinc sulfate over the olfactory mucosa of male hamsters produces obvious deficits in the ability to smell amyl acetate. However it could be argued that biologically relevant odors might still be detectable, even though potent but artificial smells were not. In Experiment 3 we tested the ability of hamsters to discriminate the odor of vaginal secretions collected from intact female hamsters, and then assessed discrimination performance following zinc sulfate administration.

\section{Materials and Method}

Six male hamsters were trained in the olfactory discrimination apparatus using procedures similar to those described in Experiment 2. The odorant source consisted of the post-estrus vaginal discharge obtained from intact female hamsters housed under a 14L:10D illumination schedule with the lights on between $10 \mathrm{a} . \mathrm{m}$. and $12 \mathrm{p} . \mathrm{m}$. Enough females were used so that a minimum of 4 females provided vaginal odor on any given day. The female cycles were such that on 3 of every 4 days, 8 or more females were in the appropriate stage of their estrous cycles. The secretion was gently extruded from the vaginal orifice and collected on small cotton swabs which were placed in Flask $B$ of the discrimination apparatus (Fig. 3). Vaginal secretions were collected each day at $11 \mathrm{a} . \mathrm{m}$. and discrimination training began immediately afterwards. If more than 3 males were being trained on any particular day, the odorant source was replenished by collecting more secretions from the same females and adding the fresh swabs to those already present in the flask. This second collection usually occurred about $3 \mathrm{hr}$ after the first; no difference could be detected in the amount of discharge available at these 2 times although some alteration in the olfactory properties of the vaginal secretion could have been taking place over this time.

Ideally, the vaginal secretions of females in behavioral estrus would provide a more appropriate odorant source. However we found that the amount of secretion available from sexually receptive females was miniscule compared to the post-estrus discharge. Although we did not carry out systematic tests, the male hamster's response to estrus vaginal secretions was not discernibly different from their response to the post-estrus discharge under a variety of 
simple preference conditions. Thus the chief advantage of utilizing the post-estrus discharge for our olfactory discrimination training was the ease with which it could be collected and the quantities available. Criterion performance levels were the same as in Experiment 2 and all hamsters were administered the saline control procedure after criterion was met. Subsequent olfactory discrimination tests were run for 4 days rather than 2 as in Experiment 2 because slight decrements in performance were observed over the first 2 days. Zinc sulfate was given after the fourth control test, and the testing schedule following this treatment was identical to Experiment 2. The effects of peripheral anosmia on sexual behavior were assessed using the same procedures as were employed in Experiment 2.

\section{Results}

The results of Experiment 3 are summarized and compared to the results of Experiment 2 in Tables 1 and 2 . Hamsters required the same number of trials to associate vaginal odor with the water reward as were required when amyl acetate was used. Saline control procedures resulted in a slight but non-significant diminution in olfactory discrimination ability. The mean number of correct responses on the 2 days of criterion performance and the first 2 days following intranasal saline was $13.6(90.7 \%)$ and $11.7(78 \%)$ respectively. This small effect was not observed in Experiment 2. However, zinc sulfate administration was equally effective in producing anosmia for the post-estrus vaginal secretion as it was when amyl acetate was used as the odorant source. In both experiments, mean performance over the first 2 days after zinc sulfate treatment was at chance levels and significantly different from performance after the control procedure $(p<0.05$, Wilcoxon test). Recovery of olfactory function appeared similar to that which occurred using amyl acetate because 3 of the 6 animals had reached criterion prior to the final test day.

Peripheral anosmia again failed to disrupt copulatory behavior (Table 2), although all 3 behavioral measures were affected. Intromission and ejaculation latencies were shorter and intromissions to ejaculation longer, during the anosmic tests than during the preceding control tests. The differences between anosmic and control conditions for all 3 measures were just large enough to achieve significance $(p<0.05$, Wilcoxon test).

\section{DISCUSSION}

Our results demonstrate conclusively that peripheral anosmia has no disruptive effects on the copulatory behavior of male hamsters in contrast to the total elimination of this behavior by olfactory bulb ablation $[19,39$, 47]. This conclusion is based on the unequivocal findings that zinc sulfate-treated animals lose the capacity to discriminate the position of either amyl acetate or the female hamster post-estrus vaginal discharge, and that while this olfactory sensitivity is lost, sexual behavior can be aroused and executed with no gross alterations in normal patterns of response. This appears to be true even in the absence of prior sexual experience (Experiment 1). Because we had no control over the rearing conditions of the inexperienced hamsters between birth and the time they entered our laboratory, we cannot be sure that some types of relevant social or sexual experience were not acquired during development. An experiment in which such control has been achieved is now in progress.

Although in both Experiments 2 and 3 the number of intromissions required to achieve ejaculation was greater after zinc sulfate treatment, this was not the case in Experiment 1. In addition, intromission and ejaculation latencies were shortened in the anosmic condition of Experiment 3. Because of the design we chose for the final 2 experiments, it is not clear whether these effects were due to the induced anosmia, or to some aspect of the behavior testing sequence we used. In all cases in which sexual behavior was tested following zinc sulfate treatment, mounts, intromissions and at least 2 ejaculations were displayed by all animals within a 5 min test.

The validity of the results we present in this study rests on a number of factors. The first concerns the extent to

TABLE 1

OlFaCtory Discrimination Performance of MAle hamsters BeFORE AND AFTER THE INDUCTION OF PERIPHERAL ANOSMIA ( $\overrightarrow{\mathrm{X}} \pm$ SEM)

\begin{tabular}{lcccc}
\hline \multicolumn{3}{c}{ Trials to Reach Criterion } & \multicolumn{3}{c}{ Percent Correct Responses } \\
\hline & & Criterion* & Control $\dagger$ & Anosmic $\ddagger$ \\
$\begin{array}{l}\text { Amyl Acetate § } \\
\text { (Experiment 2) }\end{array}$ & $137.6 \pm 11.7$ & $91.3 \pm 1.1$ & $88.0 \pm 2.2$ & $52.7 \pm 3.0$ \\
$\begin{array}{l}\text { Estrous Odor } \\
\text { (Experiment 3) }\end{array}$ & $137.5 \pm 25.7$ & $90.7 \pm 1.3$ & $78.0 \pm 3.3$ & $50.0 \pm 4.0$ \\
\hline
\end{tabular}

\footnotetext{
$* \dagger \ddagger$ Mean performance over the 2 days at criterion levels $(*)$, the first 2 test days after intranasal saline treatment $(\dagger)$, and the first 2 test days after intranasal zinc sulfate treatment $(\ddagger)$, respectively.

$\S_{N}=14$. Of the 14 animals trained to criterion, 3 were tested after saline treatment only, 6 after zinc sulfate treatment only, and 5 after both treatments in succession.

$\mathrm{a}_{\mathrm{N}}=6$. All animals were trained to criterion and then tested after both saline and zinc sulfate treatments in succession.
} 
TABLE?

SEXUAL BEHAVIOR OF MALE HAMSTERS BEIORE ANIJ AFTER THE INDUCTION G. PERIPHERAL ANOSMIA $(\overline{\mathrm{X}} \pm \text { SEM })^{*}$

\begin{tabular}{ccccccc}
\hline & \multicolumn{2}{c}{$\begin{array}{c}\text { Intromission } \\
\text { Latency }(\mathrm{Sec})\end{array}$} & \multicolumn{2}{c}{$\begin{array}{c}\text { Ejaculation } \\
\text { Latency } \text { (Sec) }\end{array}$} & $\begin{array}{c}\text { Intromission } \\
\text { to Ejaculation }\end{array}$ \\
\hline \multirow{2}{*}{ Control } & $54.3 \pm 4.9$ & $72.8 \pm 10$ & $138.6 \pm 13.4$ & $240.7 \pm 16.6$ & $8.7 \pm 1.0$ & $13.7 \pm 2.0$ \\
Anosmic & $55.3 \pm 8.8$ & $26.3 \pm 3.1$ & $159.4 \pm 22.7$ & $145 \pm 12.6$ & $13.9 \pm 3.3$ & $18.2 \pm 2.1$ \\
\hline
\end{tabular}

*Control and anosmic means \pm standard error of the mean, derived from behavior tests given before, and 2 days after intranasal zinc sulfate treatment

$+\mathrm{N}=11$

$+N=6$

which zinc sulfate treatment reliably abolishes olfactory sensitivity. Our hamsters failed to identify the location of amyl acetate or vaginal odor after zinc sulfate treatment whereas control procedures did not significantly affect the discriminability of these stimuli (Fig. 4; Table 1). In both Experiments 2 and 3 , olfactory discrimination performance was somewhat variable on the day sexual behavior was tested. However only 1 animal of 15 achieved more than 9 correct responses $(60 \%)$ on the 15 trials of that test. The 1 animal performing above this level scored 11 out of 15 correct, but its performance on subsequent trials deviated very little from chance. All males copulated to ejaculation after zinc sulfate. Although there was some variability in the behavioral measures which were obtained (Fig. 4; Table 2 ), this variability was not at all correlated with the variability displayed in the olfactory discrimination apparatus the same day.

It is possible that the animals who returned to criterion performance levels within the 8 days of olfactory testing after zinc sulfate treatment might have experienced a less severe anosmia than the animals which did not reacquire their olfactory sensitivity as rapidly. A separate analysis of the sex behavior scores was performed to compare these 2 groups. For all 3 behavioral measures, the means were quite similar and did not approach statistical significance; ejaculation latencies were actually shorter for those animals which did not meet criterion.

Our conclusion that olfactory cues are not essential for the display of sexual behavior by male hamsters is supported by other observations. Payne and Swanson [48] reported that sexually active males attempted to initiate copulation on all 4 days of the female partner's estrous cycle, suggesting that these attempts were not affected by changing olfactory stimulation throughout the cycle. Similarly, Tiefer and Johnson [66], while investigating the lordosis behavior of castrated male hamsters treated with ovarian hormones, observed that these males readily elicited mounting attempts by hormonally intact male hamsters, even when the former were untreated with estrogen. These observations have also been made in our own laboratory (unpublished). Thus whatever it is that arouses a male hamster to investigate and initiate copulation with a partner, it obviously is not an attribute associated only with females in behavioral estrus.
The differential effects of bulbectomy and peripheral anosmia on male hamster copulation are paralleled by similar differences in the mouse. Rowe and Smith [58] have recently reported that anosmic male mice mate normally even though bulbectomy abolishes this behavior [57]. In the rat, on the other hand, peripherally anosmic males show the same deficits in sexual behavior as do bulbectomized animals [33], although the deficit in this species is only partial $[7,10,30,32]$. However in the female rat under some conditions, bulbectomy and zine sulfate induced anosmia have markedly different effects on maternal behavior $[22,23]$. This also appears true for mouse killing in rats which is facilitated by bulbectomy but not by peripheral deafferentiation of the olfactory bulbs [64] or zinc sulfate treatment [1]. Peripheral anosmia in the male dog does not interfere with sexual behavior [27] although the effects of bulbectomy in this species have not been reported. Thus there appears to be no consistent theme emerging from the available evidence concerning differences between central and peripheral anosmia, but rather the effects obtained seem to depend on the particular behavior and animal studied.

When the present report was in preparation, a paper appeared [39] concerning the same problems to which our experiments were addressed. The results of this investigation were interpreted to support the hypothesis that olfactory stimulation was critical to sexual behavior in the male golden hamster. This conslusion was based on the mating performance of 11 animals which had been administered a $1.7 \%$ zinc sulfate solution in a manner somewhat comparable to the procedures we used. In behavior tests subsequent to this treatment, complete copulatory series were not scored, but the data obtained indicated that properly oriented mounting attempts were absent among 10 of 11 animals in 3 consecutive tests given up to the fourth hour after treatment. On daily tests thereafter, all hamsters had begun to mount by the fifth or sixth day. Unfortunately the conclusions based on these findings fail to consider 2 important issues. First, it is highly probable that hamsters treated with zinc sulfate are debilitated for a number of hours after this solution has been applied. This is one of the reasons we chose to test our animals $48 \mathrm{hr}$ afterwards. The second point to consider in evaluating this report is the distinct possibility that the treated hamsters 
were still anosmic when mating behavior returned. Because no tests were conducted to assess the degree of anosmia resulting from the zinc sulfate treatment, it is impossible to conclude that the absence of sexual activity was related to a loss of olfactory function. Moreover it is significant that over one-half of the animals had apparently recovered their sexual motivation by the second day following zinc sulfate treatment, which is the time we tested our hamsters and found no deficits in sexual behavior. It is unlikely that the Lisk et al. hamsters, which were treated with a zinc sulfate solution considerably less concentrated than ours $(1.7 \%$ vs. $5 \%$ ), could have lost and subsequently recovered olfactory function within 2 days because the structural differentiation of olfactory mucosa is lost 2 days after treatment with an even weaker solution (1.0\%) [63]. Thus we feel there is no rigorous evidence in the Lisk et al. study [39] which in any way minimizes the validity of the conclusions we have drawn based on the 3 experiments reported here.

The absence of mating behavior in male hamsters after their olfactory bulbs have been removed must involve something other than loss of the sense of smell. Based on a number of reports in the literature, it would appear that bulbectomy can have pronounced effects on a variety of physiological and behavioral processes seemingly unrelated to the olfactory system per se $[3,12,13,16,20,34,40$,
$43,49,50,62]$. The anatomy of central neural connections, both to and from the main and accessory olfactory bulbs is complex $[28,52,53,54,55,59,61]$. At present it is not known in what way these projections might be involved in the behavioral effects observed following bulbectomy. We are currently investigating the contribution of the accessory olfactory bulb, and intend to examine the types of neurochemical changes which may take place in the limbic system after the olfactory bulbs have been removed. In the rat, bulbectomy alters the norepinephrine content of selected brain regions [51].

We have obtained preliminary evidence which suggests that bulbectomy in some way interferes with arousal systems necessary to initiate episodes of mating activity. A number of investigators have distinguished between arousal and performance mechanisms in the control of male sexual behavior [15]. Arousing stimulation in the form of peripheral shock can facilitate sexual behavior in male rats under approapriate circumstances $[6,14,26]$. We have observed that some bulbectomized hamsters can be induced to mate by either central or peripheral stimulation, and that the mating sequences which result appear normal in terms of their component characteristics; these effects are now being systematically investigated.

\section{REFERENCES}

1. Alberts, J. R. and M. I. Friedman. Olfactory bulb removal but not anosmia increases emotionality and mouse killing. Nature 238: $454-455,1972$.

2. Alberts, J. R. and B. G. Galef, Jr. Acute anosmia in the rat: a behavioral test of a peripherally-induced olfactory deficit. Physiol. Behav. 6: 619-621, 1971.

3. Aron, C., J. Roos and G. Asch. Effect of removal of the olfactory bulbs on mating behavior and ovulation in the rat. Neuroendocrinology 6: 109-117, 1970.

4. Bandler, R. J., Jr. and C. C. Chi. Effects of olfactory bulb removal on aggression: a reevaluation. Physiol Behav. 8: 207-212, 1972.

5. Baran, D., and S. E. Glickman. "Territorial marking" in the Mongolian gerbil: a study of sensory control and function. $J$. comp. physiol. Psychol. 71 : 237-245, 1970.

6. Barfield, R. J. and B. D. Sachs. Sexual behavior: Stimulation by painful electrical shock to skin in male rats. Science 161: 392-395, 1968.

7. Beach, F. A. Analysis of the stimuli adequate to elicit mating behavior in the sexually inexperienced male rat. $J$. comp. Psychol. 33: 163-208, 1942.

8. Beach, F. A. Cerebral and hormonal control of reflexive mechanisms involved in copulatory behavior. Physiol. Rev. 47: $289-316,1967$.

9. Beach, F. A. Coital behavior in dogs: VI. Long-term effects of castration upon mating in the male. J. comp. physiol. Psychol. Monogr. 70: No. 3, Part 2, 1-32, 1970.

10. Bermant, G. and L. Taylor. Interactive effects of experience and olfactory bulb lesions in male rat copulation. Physiol. Behav. 4: 13-17, 1969.

11. Bowers, J. M. and B. K. Alexander. Mice: Individual recognition by olfactory cues. Science 158: $1208-1210,1967$.

12. Brown, G. E., E. Harrell and N. R. Remley. Passive avoidance in septal and anosmic rats using quinine as the aversive stimulus. Physiol. Behav. 6: 543-546, 1971.

13. Brown, G. E. and N. R. Remley. The effects of septal and olfactory bulb lesions on stimulus reactivity. Physiol. Behav. 6: $497-501,1971$.
14. Caggiula, A. R. and R. Eibergen. Copulation of virgin male rats evoked by painful peripheral stimulation. J. comp. physiol. Psychol. 69: 414-419, 1969.

15. Cherney, E. F. and G. Bermant. The role of stimulus female novelty in the rearousal of copulation in male laboratory rats (Rattus norvegicus). Anim. Behav. 18: 567-574, 1970.

16. Chiaraviglio, E. Effect of lesions in the septal area and olfactory bulbs on sodium chloride intake. Physiol. Behav. 4: 693-697, 1969.

17. Davidson, J. M. Activation of the male rat's sexual behavior by intracerebral implantation of androgen. Endocrinology 79: $783-794,1966$.

18. Davidson, J. M. and G. J. Bloch. Neuroendocrine aspects of male reproduction. Biol. Reprod. 1: 67-92, 1969, (Suppl. 1).

19. Doty, R. L., C. S. Carter and L. G. Clemens. Olfactory control of sexual behavior in the male and early-androgenized female hamster. Horm. Behav. 2: 325-335, 1971.

20. Douglas, R. J., R. L. Isaacson and R. L. Moss. Olfactory lesions, emotionality and activity. Physiol. Behav. 4: 379-381, 1969.

21. Field, P. M. A quantitative ultrastructural analysis of the distribution of amygdaloid fibres in the preoptic area and the ventromedial hypothalamic nucleus. Expl Brain Res. 14: $527-538,1972$.

22. Fleming, A. and $\mathbf{J}$. S. Rosenblatt. Olfactory regulation of maternal behavior in rats. I. Effects of olfactory bulb removal in experienced and inexperienced cycling and lactating females. (Submitted for publication, 1972).

23. Fleming, A. and J. S. Rosenblatt. Olfactory regulation of maternal behavior in rats. II. Effects of peripherally-induced anosmia and lateral olfactory lesions in the pup-induced virgin. (Submitted for publication, 1972).

24. Gandelman, R., M. X. Zarrow and V. H. Denenberg. Olfactory bulb removal eliminates maternal behavior in the mouse. Science 171: 210-211, 1971

25. Giantonio, G. W., N. L. Lund and A. A. Gerall. Effect of diencephalic and rhinencephalic lesions on the male rat's sexual behavior. J. comp. physiol. Psychol. 73: 38-46, 1970. 
26. Goldfoot, D. A. and M. J. Baum. Initiation of mating behavior in developing male rats following peripheral electric shock Physiol. Behal: 8: 857 863,1972

27. Hart, B. L. and C. M. Haugen. Scent marking and sexual behavior maintained in anosmic male dogs. Communs Behas: Biol. 6: $131 \cdots 135,1971$.

28. Heimer. L. Synaptic distribution of centripetal and centrifugal nerve fibres in the olfactory system of the rat. An experimental anatomical study. J. Anat. 103: $413-432,1968$

29. Heimer, L. and K. Larsson. Impairment of mating behavior in male rats following lesions in the preoptic-anterior hypothalamic continuum. Brain Res. $3: 248-263,1966 / 67$.

30. Heimer, L. and K. Larsson. Mating behavior of male rats after olfactory bulb lesions. Physiol. Behav. 2: 207 209, 1967.

31. Heimer, L. and W. J. H. Nauta. The hypothalamic distribution of the stria terminalis in the rat. Brain Res. 13: 284-297. 1969.

32. Larsson, K. Failure of gonadal and gonadotrophic hormones to compensate for an impaired sexual function in anosmic male rats. Physiol. Behav. 4:733--737, 1969.

33. Larsson, K. Impaired mating performances in male rats after anosmia induced peripherally or centrally. Brain, Behav. Evolut 4: 463-471, 1971 .

34. Larue, $C$. and J. LeMagnen. Effect of the removal of olfactory bulbs upon hyperphagia and obesity induced in rats by VMH lesion. Physiol. Behav. 5: 509-513,1970

35. Leonard, ('. M. Effects of neonatal (day 10) olfactory bulb lesions on social behavior of female golden hamsters (Mesocricetus auratus). J. (comp. physiol. Psychol. 80: 208-215. 1972 .

36. Leonard, C. M. and J. W. Scott. Origin and distribution of the amygdalofugal pathways in the rat: An experimental neuroanatomical study. J. comp. Neurol. 141: 313-330, 1971.

37. Lisk, R. D. Neural localization for androgen activation of copulatory behavior in the male rat. Endocrinology 80: $754-761,1967$.

38. Lisk. R. D. Copulatory activity of the male rat following placement of preoptic-anterior hypothalamic lesions. Expl Brain Res. 5: 306-313, 1968.

39. Lisk, R. D.. J. Zeiss and L. A. Ciaccio. The influence of olfaction on sexual behavior in the male golden hamster (Mesocricetus auratus). J. exp. Zool. 181: 69 78, 1972.

40. Loyber, I., J. A. Palma and N. I. Perassi. Changes in serum proteins due to lesion or resection of the olfactory bulbs of the rat. Experientia $26: 623-624,1970$

41. Lutge, W. G. The role of gonadal hormones in the sexual behavior of the Rhesus monkey and human: A literature survey. Archs sex. Behav. 1:61 .88, 1971

42. Malsbury, C. W. Facilitation of male rat copulatory behavior by electrical stimulation of the medial preoptic area. Physiol. Beha: 7: 797-805. 1971 .

43. Marks, H. E., N. R. Remley, J. D. Seago and D. Hastings. Effects of bilateral lesions of the olfactory bulbs of rats on measures of learning and motivation. Physiol. Behav. 7: $1 \cdots 6$. 1971 .

44. McCotter, R. E. The connection of the vomeronasal nerves with the accessory olfactory bulb in the oppossum and other mammals. Anat. Rec: 6: 299 318, 1912.

45. Moss, R. L. Modification of copulatory behavior in the female rat following olfactory bulb removal. J. comp. physiol. Psychol. 74: 374-382, 1971.

46. Mulvaney, B. D. and H. E. Heist. Regeneration of rabbit olfactory epithelium. Am. J. Anat. 131:241-252, 1971 .
47. Murphy, M. R. and G. L. Schneider. Ollactory bulb removal eliminates mating behavior in the male golden hamster. Scionc 167: $302 \cdots 303,1970$

48. Payne, A. P. and H. H. Swanson. Agnnistic behaviour hetween pairs of hamsters of the same and opposite sex in a neutral observation area. Behaviour 36:259-269, 1970 .

49. Perassi, N. I., I. Loyber and J. A. Palma. Insulin sensitivity and glucose tolerance in rats without olfactory bulbs. Neuroendocrinology 9:83-89,1972

50. Phillips, D. S. and G. K. Martin. Effects of olfactory buib ablation upon heart rate. Physiol. Behar. 7: 535-537, 1971.

51. Pohorecky, L. A., M. J. Zigmond, L. Heimer and R. J. Wurtman. Olfactory bulb removal: effects on brain norepinephrine. Proc. natn. Acad. Sci. U. S. A. 62: 1052 1055. 1969.

52. Price, J. L. and T. P. S. Powell. An experimental st udy of tho origin and the course of the centrifugal fibres to the olfactory bulb in the rat. $J$. A nat. 107: $215-237.1970$.

53. Price, J. L. and T.P.S. Powell. The afferent connections of the nucleus of the horizontal limb of the diagonal band. I. Anat. 107: 239 - 256, 1970 .

54. Price, J. L. and T. P. S. Powell. Certain observations on the olfactory pathway. $J$. Anat. 110:105-126, 1971

55. Raisman, $G$. An experimental study of the projection of the amygdala to the accessory olfactory bulb and its relationship to the concept of a dual olfactory system. Expl Brain Res. 14: $395408,1972$.

56. Rowe, F. A. and D. A. Eidwards. Olfactory bulb removal: Influences on the aggressive behaviors of male mice. Physiol. Behav. 7: $889-892,1971$.

57. Rowe, I: A. and D. A. Edwards. Olfactory bulb removal: Influences on the mating behavior of male mice. Physiol. Behav. 8: $37-\ldots 41,1972$

58. Rowe, I. A and W. E. Smith. Effects of peripherally induced anosmia on mating behavior of male mice. Psychonom. Sci. 27: $33 \cdots 34,1972$.

59. Scalia, F. A review of recent experimental studies on the distribution of the olfactory tracts in manımals. Brain Behav. Evolut.1: $101-123,1968$.

60. Schultz. E. W. Repair of the olfactory mucosa. Am. J. Path. 37: $1.19,1960$

61. Scott, J. W. and C. M. Leonard. The olfactory connections of the lateral hypothalamus in the rat, mouse and hamster. $J$. comp. Neurol. 141: $331--344,1971$.

62. Sieck, M. H. The role of the olfactory system in avoidance learning and activity. Physiol. Behav. 8: 705 -710, 1972

63. Smith, C. G. Changes in the olfactory mucosa and the olfactory nerves following intranasal treatment with one per cent zinc sulphate. Can. med. Ass. J. 39: 138-140, 1938.

64. Spector, S. A. and E. M. Hull. Anosmia and mouse killing by rats: A nonolfactory role for the olfactory bulbs. $J$ comp. physiol. Psychol. 80: 354-356, 1972.

65. Thompson, M. I. and D. A. Edwards. Olfactory bulb ablation and hormonaly induced mating in spayed female mice. Physiol. Behav. 8: 1141-1146, 1972.

66. Tiefer, L, and W. A. Johnson. Female sexual behaviour in male golden hamsters. J. Endocr. 51: 615-620, 1971.

67. Whalen, R. E. The ontogeny of sexuality. In: The Ontogeny of Vertebrate Behavior, edited by $\mathrm{H}$. Moltz. New York: Academic Press, 1971 , pp $229-261$

68. Winans, S. S. and F. Scalia. Amygdaloid nucleus: New afferent input from the vomeronasal organ. Science 170: $330 \cdots 332$, 1970 . 